\title{
Yohimbine Impairs P50 Auditory Sensory Gating in Normal Subjects
}

\author{
Lawrence E. Adler, M.D., Lee Hoffer, B.A., Herbert T. Nagamoto, M.D., \\ Merilyne C. Waldo, Ph.D., Michael A. Kisley, B.S., and Jay M. Giffith, M.D.
}

The evoked response to repeated auditory stimuli generally decreases in amplitude, a phenomenon that demonstrates the activity of sensory gating mechanisms in the central nervous system (CNS). Gating of the P50 wave of the auditory evoked response shows such behavior in normals, but not in schizophrenic or manic subjects. In mania, diminished gating of the auditory evoked response is correlated with elevated levels of noradrenergic metabolites. In animals, yohimbine, a presynaptic $\boldsymbol{\alpha}-2$ antagonist, increases noradrenergic neuronal transmission in the CNS and diminished gating of the auditory evoked response. The aim of this experiment was to test whether yohimbine causes diminished auditory sensory gating in normal human controls. Seven normal subjects with normal P50 auditory gating were treated either with $0.4 \mathrm{mg} / \mathrm{kg}$ of oral yohimbine on one day or placebo on a different day. Each subject acted as his own control. Yohimbine, but not placebo, caused a significant but transient decrease in P50 auditory gating in these subjects. Thus, increasing CNS noradrenergic neuronal transmission in normal controls can cause a transient impairment in auditory sensory gating. [Neuropsychopharmacology 10:249257, 1994]
KEY WORDS: P50; Auditory evoked poteritials; Yohimbine; Catecholamines; Schizophrenia; Mania psychosis; Sensory gating

Difficulty filtering or gating the response to environmental stimuli has been noted to be an important part of many psychotic disorders including schizophrenia (Venables 1964; McGhie and Chapman 1961). Our laboratory has used the behavior of the P50 waveform in an auditory evoked potential conditioning-testing paradigm to assess auditory sensory gating in human subjects (Adler et al. 1982). In this paradigm, normal sub-

From the University of Colorado Health Sciences Center Department of Psychiatry (LEA, LH, HTN, MCW), Denver Veterans Affairs Medical Center (LEA, LH, HTN, MCW), Department of Aerospace Engineering, University of Colorado (MAK), Denver, Colorado; Department of Psychiatry, Southwestern University School of Medicine, and Dallas Veterans Affairs MedicalCenter(JMG), Dallas, Texas.

Address correspondence to: Lawrence E. Adler, M.D., Box C26816, Psychiatry, University of Colorado Health Sciences Center, 4200 E. 9th Ave., Denver, CO 80262.

Received May 25, 1993; revised February 17, 1994; accepted February 24,1994 . jects decrease the amplitude of the P50 waveform in response to the second of two auditory clicks presented $500 \mathrm{msec}$ apart (Chapman et al. 1981; Davis et al. 1966; Erwin and Buchwald 1986; Finkenzeller and Keidel 1975; Fruhstorfer et al. 1970; Papanicolau et al. 1984, 1985; Roth and Kopell 1969). Many psychiatrically ill subjects, including most psychotic patients, do not (Adler et al. 1982, 1990; Freedman et al. 1983; Franks et al. 1983; Baker et al. 1987, 1990; Boutros et al. 1991; Judd et al. 1992; Erwin et al. 1991; Siegel et al. 1984; Waldo and Freedman 1986).

There is also increasing evidence that some deficits of P50 auditory gating may reflect increased catecholaminergic activity. For example, manic patients have impaired $\mathrm{P} 50$ auditory gating when acutely psychotic, but when they are euthymic, their P50 gating is indistinguishable from that of normal controls (Franks et al. 1983; Adler et al. 1990; Baker et al. 1987, 1990). Furthermore, the deficit in P50 gating in the manic patients is correlated with increased plasma levels of 3-methoxy4hydroxy-phenyl-glycol (MHPG), a norepinephrine metabolite. Similarly, the cold pressor test, which has 
been associated with increasing noradrenergic neuronal transmission, has been shown to cause a transient impairment in P50 auditory sensory gating in normal control subjects (Johnson and Adler 1993). Two drugs known to produce psychosis in humans, phencyclidine (PCP) and dextroamphetamine, which increase central catecholaminergic neuronal transmission, also impair auditory sensory gating in an animal model (Adler et al. 1986, 1988; Bickford-Wimer et al. 1990; Stevens et al. 1991; Miller et al. 1992).

Although this converging evidence from animal and clinical studies suggests increased noradrenergic neuronal transmission as one mechanism that decreases auditory sensory gating, the data from humans is only correlational. The aim of this study was to assess whether increasing central noradrenergic neuronal transmission would transiently impair P50 auditory sensory gating in a group of normal control subjects. One pharmacologic probe that has been used to selectively increase central noradrenergic neuronal transmission is yohimbine, a presynaptic $\boldsymbol{\alpha}-2$ antagonist. Yohimbine has precipitated acute manic episodes in some subjects (Price et al. 1984) and has precipitated panic attacks in patients with a history of panic disorder (Charney et al. 1984). It also causes an increased amplitude in the acoustic startle reflex in human subjects (Morgan et al. 1993). The peak effects of yohimbine's action in precipitating panic attacks and its effects on acoustic startle coincide with its peak effects on plasma catecholamines, that is, less than $\mathbf{3 0}$ minutes after ingestion. In animal studies, yohimbine causes a transient impairment in gating of auditory evoked potentials (Stevens et al. 1993). In this study, we used the same dose, 0.4 $\mathrm{mg} / \mathrm{kg}$, that precipitated panic disorder in predisposed individuals. Using yohimbine as a pharmacologic probe, we were able to assess the effects of a sudden rapid increase in CNS noradrenergic neuronal transmission on P50 auditory sensory gating.

\section{METHODS}

\section{Subjects}

Seven normal controls with no personal history of mental illness were recruited. None had a family history of a psychotic disorder, although one had a history of an affective disorder in a first-degree relative. All were between 21 and 35 years old. All met Research Diagnostic Criteria for Never Mentally Ill (Endicott and Spitzer 1978). Five subjects were men, two were women. All had a college degree or some graduate education. None of the subjects were being treated with medications at the time of the study, none had any illness, and none had ever abused drugs or alcohol. All subjects gave written informed consent prior to their participation in the study.

\section{Experimental Protocol}

Subjects were admitted to the Clinical Research Center of the University of Colorado Hospital between 8:00 and 9:00 A.M. on two different days, at least one week apart. Subjects had been fasting since midnight and had been asked to refrain from any alcohol or over-thecounter medication use for the previous 48 hours. They were given one to two hours to acclimate to the laboratory setting, and evoked potentials were recorded to familiarize the subject with the procedure. Up to three recordings were performed until there was gating of the P50 response to the test stimulus. Each set of evoked potentials consisted of 16 trials. Two sets of baseline evoked potentials were then obtained. The subject was then given a gelatin capsule containing either $0.4 \mathrm{mg} / \mathrm{kg}$ of yohimbine or placebo; the order of administration was decided by randomization. Four subjects received yohimbine the first day, and three subjects received placebo the first day. Each subject completed both the placebo and drug portions of the study. Subjects were given at least one week between study days; most subjects had two to three weeks between experimental days.

Beginning 15 minutes after drug administration, three 16-trial sets of evoked potentials were recorded. In each case, the post-drug recordings were completed by 30 to 35 minutes after drug administration. Two 16trial sets of evoked potentials were recorded one hour after drug administration, and an additional set was recorded two hours after drug administration. Only one averaged evoked potential for one subject was discarded due to artifact. Up to $20 \%$ of trials were rejected on line because of noise. Thus, some subjects needed 20 evoked potential trials to generate one set of 16 trials. A total of 111 evoked potential averages were used in the study.

Blood pressure and pulse were recorded after the evoked potentials were completed for each time period. In addition, subjects completed a brief self-rated test, the POMS (Profile of Mood States, McNair et al. 1971) examination at each time period.

\section{Evoked Potential Recording}

Evoked potential recording was performed with the subjects supine and their heads well supported on pillows. The recordings were performed and analyzed by an investigator blind to the pharmacologic treatment condition. The subjects were instructed to keep their eyes open and fixed on a distant target. Electroencephalographic activity (EEG) was recorded from a gold disk electrode affixed to the vertex, referenced to nose, with a forehead ground. Electrooculogram (EOG) was recorded from electrodes on the right superior orbit and 
lateral canthus. The signals were amplified 20,000 times by a $22 \mathrm{M} \Omega$ impedance amplifier with bandpass filters $(-50 \%$ ) between 1.0 and $300 \mathrm{~Hz}$ (model $7 \mathrm{p} 511$, Grass Instruments, Quincy, MA). The EEG was monitored on an IBM AT compatible computer (Epson Equity III, Torrance, CA) with an analog interface (Data Translation DT 101, Marlboro, MA). Data was acquired at 1000 $\mathrm{Hz}$ digitization rate. Individual trials were rejected when there was evidence of alpha waves or slow wave activity, which causes changes in P50 gating (Griffin et al. 1993). Individual trials were also rejected or replayed off line if the tracing contained a startle response to the auditory stimulus, which is seen as EOG activity greater than $50 \mu \mathrm{V}$ or as a negative-positive complex greater than $50 \mu \mathrm{V}$ in the EEG occurring $30 \mathrm{msec}$ after the stimulus, which reflects activity originating in the neck muscles (Robinson and Rudge 1982). In this study, approximately $20 \%$ of trials were dropped on line due to such artifacts. Each average evoked potential consisted of 16 individual trials.

Auditory stimuli were presented in trains of pairs in a conditioning-testing paradigm, with $0.5 \mathrm{~s}$ intrapair interval and a $10 \mathrm{~s}$ interstimulus interval. The stimulus was an 0.04 msec pulse, amplified with a bandwidth between 20 and $12,000 \mathrm{~Hz}$ and delivered through headphones. Mean intensity was $70 \mathrm{~dB}$ SPL, as measured at the subject's ear by a sound meter. If the subject showed startle reactions or EOG activity to the stimulus, the intensity was reduced by $5 \mathrm{~dB}$ (Freedman 1990). One subject required such a decrease in stimulus intensity. Changes in sound intensity were not made after the baseline period.

The averages were digitally filtered with a recursive high-pass double-time autoregressive filter and a 7 point low-pass digital smoothing routine $(A=0.95$, Coppola 1979). Each filter was applied twice in both the forward and reverse direction, to increase rolloff and to preserve waveform latency. Low-pass filtering was performed by averaging each point with the three points before and after. This technique was also performed twice. This filtering technique causes a decrease of $70 \%$ in frequencies below $10 \mathrm{~Hz}$ or above 250 $\mathrm{Hz}$. A previously described computer algorithm (Nagamoto et al. 1989) was used to identify and quantitate P50. The algorithm identified the conditioning P50 waveform as the most positive peak between 40 and $80 \mathrm{msec}$ after the first stimulus. If more than one peak was identified, the later one was selected. The test P50 was identified as the most positive peak with a latency from the test response within $10 \mathrm{msec}$ of the latency of the conditioning P50 response. This criterion was determined from the distribution of conditioning and test P50 wave latencies in a previous study (Nagamoto et al. 1991). The test amplitude was measured relative to its preceding negativity. The amplitude of the test P50 wave ( $\mathrm{T}$ ) divided by the amplitude of the con- ditioning P50 wave (C), expressed as percent and termed here the $\mathrm{T} / \mathrm{C}$ ratio, was used as a measure of sensory gating.

Sixteen trial averages were used because the speed of the yohimbine effect precluded the use of longer recording periods. To assess whether the conditioning and testing response could be discriminated from noise in such averages, a set of 16 single trial recordings and their average were analyzed. The time points used for measurement of the P50 and the preceding negativity were established in the average waveform for both the conditioning and testing response. An equal time period was demarcated in the prestimulus period, ending at the delivery of the conditioning stimulus. Then, the amplitude measurements of prestimulus activity, the conditioning P50 wave, and the test P50 wave were made in each of the 16 individual responses, using these time points. To estimate the variability of each measure, the mean value was divided by the standard error of the mean to determine a Student's $t$-score with 15 degrees of freedom. Single tailed probability values were used because of the assumption that P50 is positive. The $t$-score for the prestimulus activity was 0.01 (NS), whereas the $t$-score for the poststimulus conditioning wave was $1.87(p<$ $.05)$ and for the poststimulus test wave was $1.90(p<$ $.05)$. Thus, the P50 waves measured in the 16 trial paradigm are a statistically significant characteristic of the poststimulus evoked response, distinguishable from background activity.

\section{Statistical Analysis}

Because of the small sample size and because of the different number of trials in each time period, the experiment was initially planned and analyzed as a randomized block design analysis of variance (ANOVA) with two treatment effects (placebo and drug) and four time effects (baseline, 30 minutes post, 1 hour post, and two hours post). Post hoc $t$-tests were performed for comparison of individual contrasts only if protected by a significant ANOVA (Wilkinson 1990). A repeated measure ANOVA was then calculated using the means for each subject for each treatment at each time. Only four planned $t$-tests were done. Three were for pulse, systolic, and diastolic blood pressures between baseline and 30 minute post-yohimbine conditions. The fourth comparison compared the P50 ratio between placebo and yohimbine at 30 minutes past drug. This comparison was planned to coincide with peak effects as assessed by previous investigators (Charney et al. 1984). All values are expressed as mean and standard deviation for each condition for the seven subjects. All probability values are two-tailed unless specifically noted. 


\section{SUBJECI 1}

BASELINE

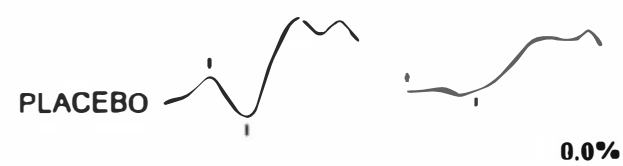

$0.0 \%$
HALF HOUR POST

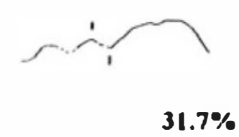

$31.7 \%$
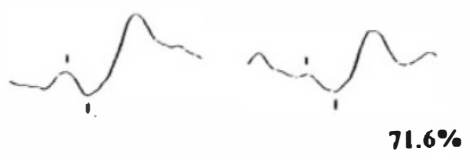

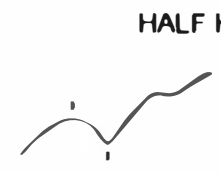

$9.5 \%$

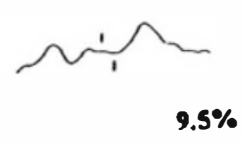

DRUG<smiles>CCCCCCCCCCCCC</smiles>

BASELINE

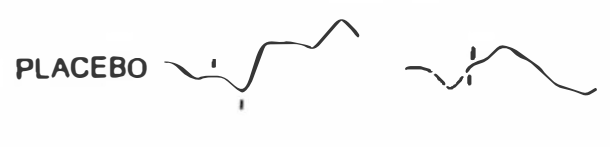

$0.0 \%$
HALF HOUR POST

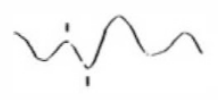

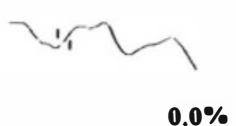
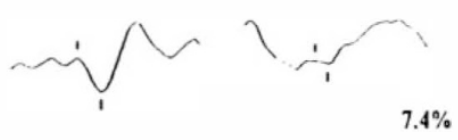

HOUR POST

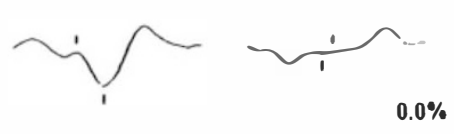

\section{SUBJECT 2}
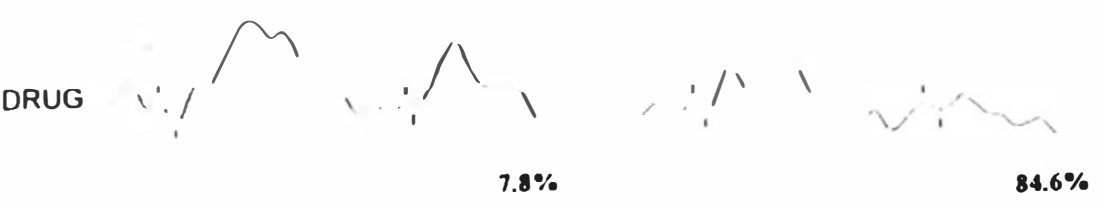
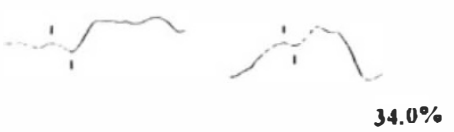

Figure 1. Two subjects at three different times: baseline, 30 minutes post drug or placebo, and 1 hour post drug or placebo for both the drug and placebo days. The first waveform in each pair is the conditioning waveform; the second waveform is the test waveform. The $\mathrm{T} / \mathrm{C}$ ratio as a percentage is given below each pair. Tick marks indicate the P50 waveform as measured by the computer algorithm. Superimposed tick marks in the test waveform or lack of a discernible waveform between the tick marks indicate the P50 waveform is absent (zero amplitude). The first subject has $\mathrm{T} / \mathrm{C}$ ratios below $32 \%$ in all three placebo conditions, but has significantly impaired P50 gating ( $\mathrm{T} / \mathrm{C}$ ratio $=71.6 \%$ ) one half hour after $0.4 \mathrm{mg} / \mathrm{kg}$ of yohimbine, which returns to the normal range of $7.4 \%$ one hour after yohimbine. The second subject has $\mathrm{T} / \mathrm{C}$ ratios of $0 \%$ in all three placebo times, but has an increased $\mathrm{T} / \mathrm{C}$ ratio of $84.6 \%$ one half hour after drug, which returns to $34 \%$ by one hour after drug. These two subjects illustrate the rapid, but relatively brief impairment of P50 auditory gating caused by a sudden increase in noradrenergic neuronal transmission.

\section{RESULTS}

Administration of yohimbinecaused a transient but pronounced impairment in P50 auditory sensory gating. Figure 1 shows representative waveforms from two subjects at the baseline, 30 minute, and one hour time intervals. For each of these two subjects shown, the T/C ratio peaked within 30 minutes after yohimbine and the effect was lost by one hour. Figure 2 shows a similar effect on the mean ratios for all seven subjects.

An analysis of variance pooling averages from all subjects permitted use of all ratios obtained, even if different subjects did not have equal numbers of averaged evoked potentials at each time period. This anal- ysis showed a significant effect of treatment $(F=8.00$, $d f=1,103, p<.006)$ but not of time $(F=2.45, d f=3,103$, $p<.07)$ or of treatment by time $(F=1.13, d f=3,103$, NS). An analysis of variance was also done examining the effect of treatment, subject, and treatment by subject interaction on the P50 ratio. Once again, there was a significant effect of treatment $(F=8.22, d f=1,97$, $p<.005)$, but not of subject $(F=0.995, d f=6,97, p<$ $.433)$ or of subject by treatment $(F=0.995, d f=0.113$, $p<$.995). The means for each subject under each treatment condition were then used in a univariate repeated measures analysis of variance, which also showed a significant effect of yohimbine treatment $(F=9.65, d f=$ $1,12, p<.01)$, but no overall significant effect of time 


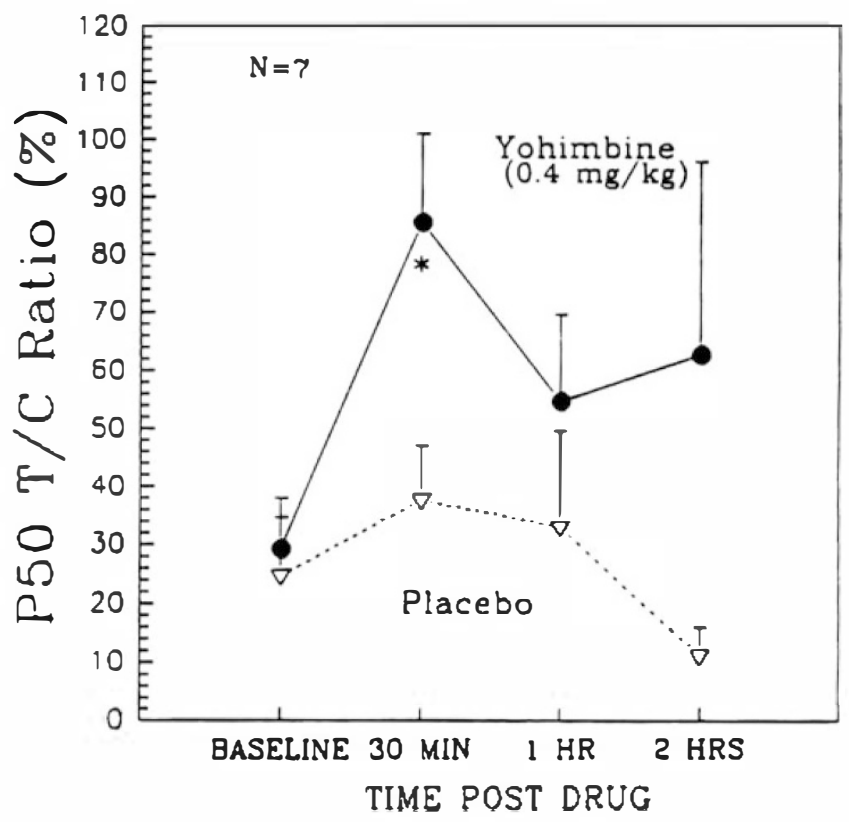

Figure 2. Maximum effect of yohimbine on each subject. P50 $\mathrm{T} / \mathrm{C}$ ratio (\%) on the vertical axis versus time after drug administration on the horizontal axis. All values are mean \pm SEM. There is a significant difference between the yohimbine and placebo curves $(F=8.00, d f=1,103, p<.006)$. The planned $t$-test between yohimbine and placebo is significant at one half hour post drug $(t=2.64, d f=40, p<.01)$ and is indicated by an asterisk.

$(F=1.41, d f=3,36, p<.26, \mathrm{NS})$ or of treatment by time $(F=0.88, d f=3,36, p<.46, N S)$. However, there was a significant difference between $\mathrm{T} / \mathrm{C}$ ratios at 30 minutes after drug versus placebo administration when the 21 placebo and 21 yohimbine evoked potential averages were compared. The mean $\mathrm{T} / \mathrm{C}$ ratio 30 minutes post yohimbine was $85.4 \% \pm 70.8 \%$, versus $37.7 \% \pm$ $43.2 \%$ post-placebo $(t=2.64, d f=40, p<.01)$. By one and two hours after the administration of yohimbine, the treatment effect had largely disappeared. Figure 3 shows the mean baseline P50 ratios and the maximal P50 ratios reached during the first hour after yohimbine treatment for each of the seven subjects. Two hours after the drug was administered, two of the seven subjects still had significantly elevated $\mathrm{T} / \mathrm{C}$ ratios, although the remaining five had returned to $\mathrm{T} / \mathrm{C}$ ratios below $50 \%$. This is the explanation for the increased variance observed at the two hour mark.

There was no significant effect of yohimbine on either P50 conditioning amplitude or on latency (Tables 1 and 2). However, for amplitude, both the overall ANOVA $(F=3.21, d f=3,103, p<.03)$ and the univariate repeated measures ANOVA $(F=6.13, d f=3,36$, $p<.002$ ) showed a significant effect of treatment time within subjects, but not of treatment by time. As can be seen in Table 1, the largest decrease in overall means

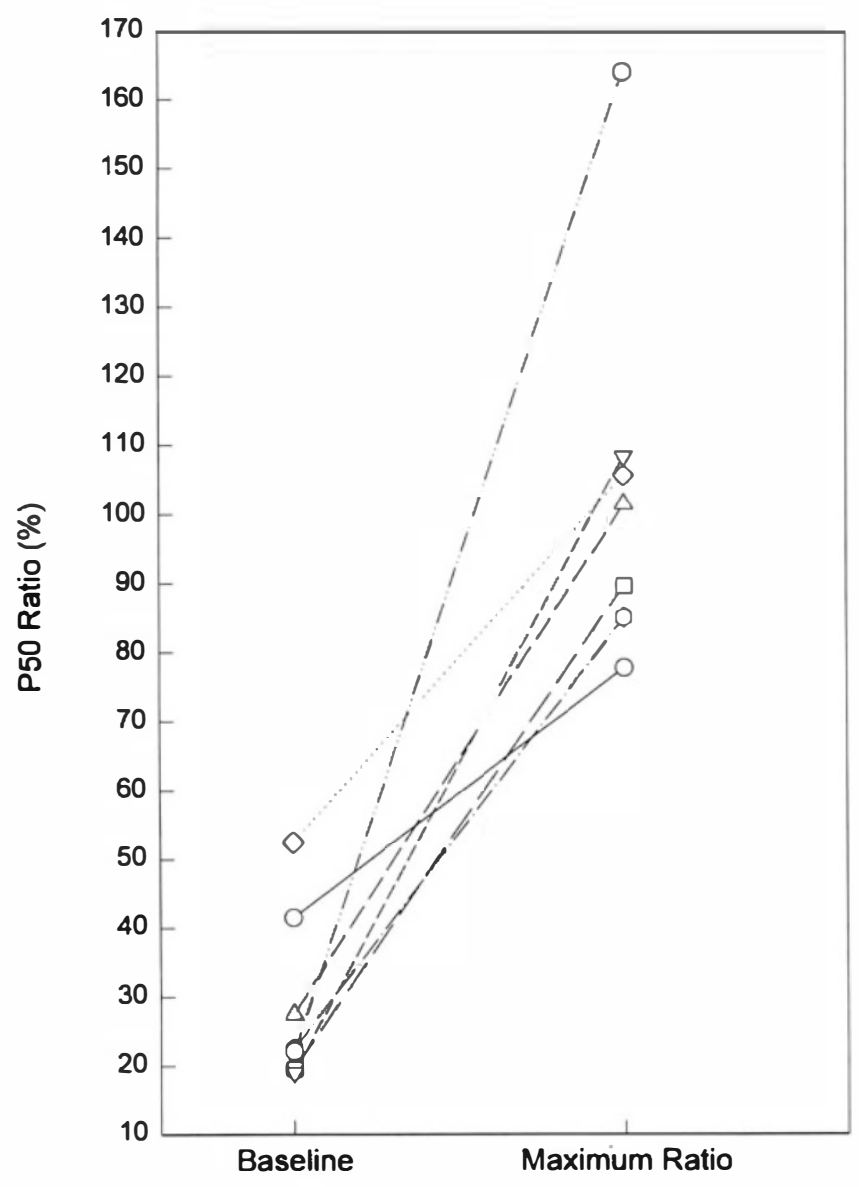

Figure 3. The figure shows the mean baseline for each subject on the day the subject took yohimbine followed by the increased P50 T/C ratio for each subject after yohimbine treatment. The vertical axis is the P50 (T/C) ratio expressed as a percentage. The mean baseline is the mean of the two baseline averages for each subject. Each subject is indicated by a different symbol and different line. All but one subject had P50 ratios of less than $40 \%$. Five of the subjects had baseline $\mathrm{P} 50$ ratios less than $30 \%$. Four of the subjects clustered at approximately $20 \%$, which is the reason for the overlapping symbols in the Baseline column. The column "Maximum Ratio" shows the maximum effect of yohimbine for each subject at either 30 minutes or 1 hour after drug ingestion. Five of the seven subjects had peak P50 ratios at 30 minutes post drug, whereas two of the subjects had a delayed peak at 1 hour post drug. The lines connect the baseline value to the maximal posttreatment value for each subject. The maximal P50 ratios graphed represent the means of two to three averages for each subject. All but one subject returned to $\mathrm{P} 50 \mathrm{~T} / \mathrm{C}$ ratios of less than $40 \%$ at two hours post drug. Four of the subjects had returned to $\mathrm{P} 50 \mathrm{~T} / \mathrm{C}$ ratios of less than $10 \%$ at 2 hours post drug.

occurred at the one hour time interval. Because of the significant effect of time on amplitude, we also looked for an effect of amplitude on $\mathrm{P50}$ ratio. There was a small but significant correlation between amplitude and P50 ratio, $r=-0.24, p<.01$, accounting for $5.8 \%$ of the 
Table 1. Amplitude of the P50 Conditioning Response During Treatment

\begin{tabular}{lcccc}
\hline & Baseline & 30 Minutes & 1 Hour & 2 Hours \\
\hline Yohimbine & $4.4 \pm 2.3$ & $3.1 \pm 2.5$ & $3.1 \pm 2.6$ & $4.4 \pm 2.3$ \\
Placebo & $5.1 \pm 3.4$ & $3.3 \pm 2.6$ & $2.5 \pm 1.8$ & $3.7 \pm 1.9$
\end{tabular}

All values are in $\mu \mathrm{V}$, mean $\pm \mathrm{SD}$.

variance in the P50 ratio. An analysis of covariance on ratio could not be performed because there was a significant interaction between treatment and amplitude, indicating nonparallel slopes. However, in any use of the generallinear model on a ratio measure, there is the possibility that a correlation between a linear measure (amplitude) and a nonnormally distributed nonlinear measure (ratio) could be spurious. Therefore, we used the logarithmic transformation of the P50 ratio in a second ANOVA. In order to avoid dropping data points, any P50 ratio of zero was recoded as .001, since zero cannot be logarithmically transformed. Because the initial analysis of variance did not yield a significant treatment by amplitude interaction, an analysis of covariance was performed. Drug treatment was significant $(F=5.5, d f=1,94, p<.021)$. In the analysis of covariance, the effect of amplitude just missed significance $(F=3.63, d f=1,94, p<.06)$. In this case, the Pearson's correlation between amplitude and the $\log$ of the P50 ratio was only $0.20, p<.15$, NS. Thus, when a logarithmic transformation of the P50 ratio was used, there was no significant linear correlation between amplitude and sensory gating, nor was there a direct effect of amplitude on P50 ratio in the analysis of covariance.

The effect of yohimbine on pulse and blood pressure was compared as a difference between the baseline and half-hour treatment values for the placebo and drug days. There were no significant differences among trials for the placebo day. On the drug day, the only effect of yohimbine was on systolic blood pressure 30 minutes after drug treatment. Mean systolic blood pressure prior to treatment was $100.9 \mathrm{~mm} \mathrm{Hg}$ and after drug was $113.1 \mathrm{~mm} \mathrm{Hg}$ (paired $t$-test $=2.9, d f=6, p<.028$ ). There were no significant effects on diastolic blood pressure or pulse, nor were there any other differences at the other time intervals. Finally, none of the subscales of the POMS changed significantly during the experiment, although all seven subjects felt "tired" and restless at the end of both days.

\section{DISCUSSION}

Administration of yohimbine transiently impaired P50 auditory sensory gating in this normal control population. A small but significant increase in systolic blood pressure was noted at the 30 minute postdrug time point, which was consistent with previous investigators. Since the evoked responses were recorded prior to obtaining vital signs, the blood pressures were taken later than the usual peak 20 minute time point; thus we might have inadvertently biased the experiment against finding an even larger difference in systolic blood pressures. We did not expect to see changes in a behavioral rating scale in young, healthy subjects. However, most reported some subjective stress by the end of the lengthy recording sessions, both in placebo and drug conditions.

Although yohimbine principally increases noradrenergic neuronal transmission, at high dosages yohimbine may also bind dopaminergic autoreceptors, thus increasing dopaminergic neuronal transmission as well (Scatton et al. 1980). However, Stevens et al. (1993), found that coadministering SCH 23390, a selective $D_{1}$ antagonist with yohimbine, did not block the yohimbine-induced impairment in auditory sensory gating in an animal model. Similarly, Gurgius and Uhde (1990) found that $20 \mathrm{mg}$ of yohimbine did not significantly increase plasma HVA levels, even in patients prone to panic disorder. Thus, the action of yohimbine on auditory gating would appear to be mediated by norepinephrine.

Evidence from animal studies suggests that gating of the N40 waveform in the rat, which behaves homologously to the P50 waveform in human subjects, has its origins in CA3 of the hippocampus (Bickford-Wimer et al. 1990; Miller et al. 1992). Depth probe studies in human subjects suggest that the P50 waveformalso may have its origins either in the superior temporal lobe or in hippocampus (Freedman et al. 1991). In animals, norepinephrine decreases synaptic inhibition in rat hip-

Table 2. P50 Latency During Treatment

\begin{tabular}{llccc}
\hline & Baseline & 30 Minutes & 1 Hour & 2 Hours \\
\hline Yohimbine & $55.1 \pm 1.1$ & $55.1 \pm 3.1$ & $54.1 \pm 6.4$ & $57.0 \pm 5.7$ \\
Placebo & $55.4 \pm 5.1$ & $56.9 \pm 3.7$ & $57.2 \pm 5.4$ & $56.3 \pm 7.1$ \\
\hline
\end{tabular}

All values are in msec, mean $\pm S D$. 
Table 3. Blood Pressure and Pulse During Treatment

\begin{tabular}{lcccr}
\hline & Baseline & 30 Minutes & 1 Hour & 2 Hours \\
\hline Yohimbine & & & & \\
$\quad$ Systolic BP & $100.9 \pm 8.3$ & $113.1 \pm 13.5$ & $111.7 \pm 11.7$ & $110.9 \pm 14.5$ \\
Diastolic BP & $64.4 \pm 8.2$ & $67.9 \pm 10.5$ & $74.1 \pm 9.9$ & $66.7 \pm 11.4$ \\
$\quad$ Pulse & $55.4 \pm 2.8$ & $55.9 \pm 7.9$ & $60.7 \pm 7.5$ & $58.9 \pm 7.8$ \\
Placebo & & & & \\
$\quad$ Systolic BP & $109.7 \pm 11.6$ & $102.8 \pm 10.9$ & $108.8 \pm 15.1$ & $108.3 \pm 11.1$ \\
Diastolic BP & $67.3 \pm 11.8$ & $68.8 \pm 10.3$ & $70.6 \pm 9.0$ & $71.0 \pm 11.5$ \\
Pulse & $64.0 \pm 11.9$ & $60.0 \pm 12.7$ & $65.6 \pm 15.9$ & $62.3 \pm 15.0$ \\
\hline
\end{tabular}

All values are mean \pm SD. Pulse is in beats per minute, pressure in $\mathrm{mm} \mathrm{Hg}$.

pocampus, through both presynaptic and postsynaptic mechanisms (Madison and Nicoll 1988; Newberry and Nicoll 1984; Dutar and Nicoll 1988).

The impairment of auditory sensory gating by norepinephrine may be relevant to disorders in which auditory sensory gating is impaired when patients are acutely ill, such as mania and other illnesses in which there is increased noradrenergic neuronal transmission (Franks et al. 1983; Adler et al. 1990; Baker et al. 1987). In contrast, schizophrenic patients and half of their firstdegree relatives appear to have impaired P50 auditory gating as a trait rather than as a state deficit (Siegel et al. 1984; Waldo et al. 1991; Freedman et al. 1991). In schizophrenic patients, this impairment of P50 auditory gating persists even when they are treated with enough neuroleptic to cause mild extrapyramidal symptoms (Freedman et al. 1983; Adler et al. 1990). Such dosages probably block both dopamine and norepinephrine at the postsynaptic receptor(Freedman 1977). These findings suggest that state-dependent, reversible deficits in P50 gating may be due to increased noradrenergic neuronal transmission (Waldo et al. 1992), but that in schizophrenia, in which the P50 gating deficit appears to be an inherited triat (Waldo et al. 1991; Siegel et al. 1984), the deficit may be more related to deficits in other neurotransmitter systems. For example, impairment of nicotinic transmission to area CA3 of the hippocampus results in direct impairment of auditory gating (Luntz-Leybman and Freedman 1992), and nicotine normalizes P50 gating in schizophrenics and their relatives (Adler et al. 1992, 1993).

\section{ACKNOWLEDGMENT}

Supported by USPHS Grants MH44212, MH38321, MH00728, 502 RR00051 from the Division of Research Resources, and the Veterans Affairs Medical Research Service.

\section{REFERENCES}

Adler LE, Pachtman E, Franks RD, Pecevich M, Waldo MC, Freedman R (1982): Neurophysiological evidence for a defect in neuronal mechanisms involved in sensory gating in schizophrenia. Biological Psychiatry 17:638-654

Adler LE, Rose GM, Freedman R (1986): Neurophysiologic studies of sensory gating in rats: Effects of amphetamine, phencyclidine and haloperidol. Biol Psychiatry 21:787798

Adler LE, Pang K, Gerhardt G, Rose GM (1988): Modulation of the gating of auditory evoked potentials by norepinephrine: Pharmacological evidence obtained using a selective neurotoxin. Biol Psychiatry 24:179-190

Adler LE, Gerhardt GA, Franks R, Baker N, Nagamoto H, Drebing C, Freedman R (1990): Sensory physiology and catecholamines in schizophrenia and mania. Psychiatry Res 31:297-309

Adler LE, Hoffer LJ, Griffith J, Waldo M, Freedman R (1992): Normalization of deficient auditory gating in the relatives of schizophrenics by nicotine. Biological Psychiatry 32: 607-616

Adler LE, Hoffer LD, Wiser A, Freedman R (1993): Normalization of auditory physiology by cigarette smoking in schizophrenic patients. Am J Psychiat 150:1856-1861

Baker N, Adler LE, Franks RD, Waldo M, Berry S, Nagamoto H, Muckle A, Freedman R (1987): Neurophysiological assessment of sensory gating in psychiatric inpatients: Comparisonbetween schizophrenia and other diagnoses. Biol Psychiatry 22:603-617

Baker NJ, Staunton M, Adler LE, Gerhardt GA, Drebing C, Waldo M, NagamotoH, Freedman R(1990): Sensory gating deficits in psychiatric inpatients: relation to catecholamine metabolites in different diagnostic groups. Biol Psychiatry 27:519-528

Bickford-Wimer PC, Nagamoto H, Johnson R, Adler LE, Egan M, Rose GM, Freedman R (1990): Auditory sensory gating in hippocampal neurons: A model system in the rat. Biol Psychiatry 27:183-192

Boutros NN, Overall J, Zouridakis G (1991): Test-retest reliability of the P50 mid-latency auditory evoked response. Psychiatry Res 39:181-192

Chapman CR, Colpitts YH, MayenkoJK, Gaglioardi GJ (1981): Rate of stimulus repetition changes evoked potential amplitude: Dental and auditory modalities compared. Exp Brain Res 43:246-252

Charney DS, Heninger GR, Breier A (1984): Noradrenergic function in panic anxiety: Effects of yohimbine in healthy subjects and patients with agoraphobia and panic disorder. Arch Gen Psychiatry 41:751-763

Coppola R (1979): Isolating low frequency activity in EEG spec- 
trum analysis. Electroencephalogr Clin Neurophysiol 46:101-105

Davis H, Mast T, Yoshie N, Zerlin S(1966): The slow response of the human cortex to auditory stimuli: Recovery process. Electroencephalogr Clin Neurophysiol 21:105-113

Dutar P, Nicoll RA (1988): A physiological role for GABAB receptors in the central nervous system. Nature 332: $156-158$

Endicott J, Spitzer RL (1978): Schedule for Affective Disorders and Schizophrenia-Life-time Version (SADS-L). New York: New York State Psychiatric Institute

Erwin RJ, Buchwald JS (1986): Midlatency auditory evoked responses: Differential recovery cycle characteristics. Electroencephalogr Clin Neurophysiol 64:417-423

Erwin RJ, Mawhinney-Hee M, Gur RC, Gur RE (1991): Midlatency auditory evoked responses in schizophrenia. Biol Psychiatry 30:430-442

Finkenzeller P, Keidel WD (1975): Correlates of auditory perception in averaged prestimulatory EEG-DC recordings. In Quantitative Analysis of the EEG, Methods and Applications. AEG-Telefunken, 1975; reprinted in Keidel W, Kallert S, Korth M (eds). The Physiological Basis of Hearing. Stuttgart: Georg Thieme Verlag, 1983, p 198

Franks RD, Adler LE, Waldo M, Alpert J, Freedman R (1983): Neurophysiological studies of sensory gating in mania: Comparison with schizophrenia. Biol Psychiatry 18: 989-1005

Freedman R (1977): Interactions of antipsychotic drugs with norepinephrine and cerebellar neuronal circuitry: Implications for the psychobiology of psychosis. Biol Psychiatry 12:181-197

Freedman R (1990): Evoked response to repeated auditory stimuli (letter). Biol Psychiatry 28:1065-1066

Freedman R, Adler LE, Waldo MC, Pachtman E, Franks RD (1983): Neurophysiological evidenced for a defect in inhibitory pathways in schizophrenia: Comparison of medicated and drug-free patients. Biol Psychiatry 18:537-551

Freedman R, Waldo M, Bickford-Wimer P, Nagamoto H (1991): Elementary neuronal dysfunction in schizophrenia. Schizophr Res 4:233-243

Fruhstorfer H, Soveri P, Jarvilehto T (1970): Short-cerm habituation of the auditory evoked response in man. Electroencephalogr Clin Neurophysiol 28:153-159

Griffith JM, Waldo M, Adler LE, Freedman R(1993): Normalization of auditory sensory gating in schizophrenics after a brief period for sleep. Psychiatry Res 49:29-39

Gurguis GN, Uhde TW (1990): Effect of yohimbine on plasma homovanillic acid in panic disorder patients and normal controls. Biol Psychiatry 28:292-296

Johnson M, Adler LE (1993): Transient impairment of P50 auditory sensory gating by a cold-pressor test. Biol Psychiatry 33:380-387

Judd LL, McAdams LA, Budnick B, Braff DL (1992): Sensory Gating Deficits in Schizophrenia: New Results. Am J Psychiatry 149:488-493

Luntz-Leybman V, Bickford PC, Freedman R (1992): Cholinergic gating of response to auditory stimuli in rat hippocampus. Brain Res 587:130-136

Madison DV, Nicoll RA (1988): Norepinephrine decreases syn- aptic inhibition in the rat hippocampus. Brain Res 442: 131-138

McGhie A, Chapman J (1961): Disorders of attention and perception in early schizophrenia. Br J Med Psychol 34: 103-116

McNair DM, Lorr M, Droppelman IP (1971): Profile of Mood States. Education and Industrial Testing Service, San Diego: CA

Miller CL, Bickford-Wimer PC, Leybman V, Adler LE, Gerhardt G, Freedman R (1992): Phencyclidine induces a physiological feature of psychosis. Neuropharmacology 31:1041-1048

Morgan CA III, Southwick SM, Grillon C, Davis M, Krystal JH, Charney DS (1993): Yohimbine-facilitated acoustic startle reflex in humans. Psychopharmacology 110:342346

Nagamoto HT, Adler LE, Waldo MC, Freedman R (1989): Sensory gating in schizophrenics and normal controls: Effects of changing stimulation interval. Biol Psychiatry 25: 549-561

Nagamoto HT, Adler LE, Waldo MC, Griffith J, Freedman $R$ (1991): Gating of auditory response in schizophrenics and normal controls: Effects of recording site and stimulation interval on the P50 wave. Schizophr Res 4:31-40

Newberry NR, Nicoll RA (1984): Direct hyperpolarizing action of baclofen on hippocampal pyramidal cells. Nature 308:450-452

Papanicolau AC, Loring DW, Eisenberg HM (1984): Agerelated differences in recovery cycle of auditory evoked potentials. Neurobiol Aging 5:291-295

Papanicolau AC, Loring DW, Eisenberg HM (1985): Evoked potential attenuation in the two-tone paradigm. Int J Psychobiol 3:23-28

Price LH, Charney DS, Heninger GR (1984): Three cases of manic symptoms following yohimbine administration. Am J Psychiatry 141:1267-1268

Robinson K, Rudge P (1982): Centrally generated evoked potentials. In Halliday AM, (ed), Evoked Potentials in Clinical Testing. London: Churchill Livingstone, pp 368-372

Roth WT, Kopell BS (1969): The auditory evoked response to repeated stimuli during a vigilance task. Psychophysiology 6:301-309

Scatton B, Zivovic B, Dedek K (1980): Antidopaminergic properties of yohimbine. J Pharmacol Exp Ther 215:494-499

Siegel C, Waldo M, Mizner G, Adler LE, Freedman R (1984): Neurophysiological evidence for deficits in sensory inhibition in schizophrenic patients and their relatives. Arch Gen Psychiatry 41:607-612

Stevens KE, Fuller LL, Rose GM (1991): Dopaminergic and noradrenergic modulation of amphetamine-induced changes in auditory gating. Brain Res 555:91-98

Stevens KE, Meltzer J, Rose GM (1993): Disruption of sensory gating by the $\alpha-2$ selective noradrenergic antagonist yohimbine. Biol Psychiatry 33:130-132

Venables P (1964): Input dysfunction in schizophrenia. In Mahler BA (ed), Progress in Experimental Personality Research. New York, Academic Press, pp 1-70

Waldo MC, Freedman R (1986): Gating of auditory evoked responses in normal college students. Psychiatry Res 19:233-239 
Waldo M, Carey G, Myles-Worsley M, Cawthra E, Adler LE, Nagamoto HT, Wender P, Byerley W, Plaetke R, Freedman R (1991): Co-distribution of sensory gating deficit and schizophrenia in multi-affected families. Psychiatry Res 39:257-268

Waldo M, Gerhardt G, Baker N, Drebing C, Adler LE, Freed- man R (1992): Auditory sensory gating and catecholamine metabolism in schizophrenic and normal subjects. Psychiatry Res 44:21-32

Wilkinson L (1990): SYSTAT: The system for statistics. Evanston, IL: SYSTAT, Inc. 